\title{
Macro-Micro Scale Observation of Cyclic Hardening-Softening and Precipitates Zone of C460
}

\author{
Aezeden Mohamed \\ Faculty of Engineering and Applied Science, Memorial University, St. John's, NL, A1B $3 X 5$
}

\begin{abstract}
Three sets of age hardened aluminum-lithium alloy C460 specimens were produced by oil quenching, air cooling, and furnace cooling and subjected to cyclical, symmetric tension-compression testing. On examination of microstructures with the aid of scanning electron microscopy, precipitates free zones were identified adjacent to grain boundaries. It was also found that the specimens with the smallest precipitates free zones exhibited the highest fatigue strengths.
\end{abstract}

Keywords: - Air, cooling, cyclic, furnace, oil, precipitates, quenched.

\section{INTRODUCTION}

Aluminum-lithium alloy has better mechanical and microstructural properties compared to conventional alloys such as aluminum-copper, aluminum-magnesium and, aluminum-zinc [1,2]. Further, aluminum-lithium alloys are more attractive to the aerospace industry because of their light weight and lower cost compared to newer materials such as titanium alloys [3]. Although, aluminum-lithium alloys are promising alloys for the aerospace industry they have some short comings, including a low ductility, especially at low temperatures, and poor anisotropy of properties [4-7]. Efforts have been made to overcome these deficiencies. The microstructurally controlled strength of the alloy results from age hardening as for the conventional alloys. The age hardening of the alloy forms precipitates free zones which grow along grain boundaries. Increasing aging time and aging temperature enhance the precipitates free zone (PFZ) formation. Hence, lowering of the aging time is advised in order to minimize precipitates free zones (PFZ) [8].

Recently, a new aluminum-lithium alloy type C460 was developed by Alcoa Aerospace Engineered Products that has a higher fracture toughness and ductility that earlier grade of this alloy. This paper will describe an investigation into the effect of age hardening on the fatigue strength of the C460 alloy.

\section{EXPERIMENTAL PROCEDURE}

The material used for the current study was aluminum lithium alloy $\mathrm{C} 460$ rod stock as received with a chemical composition in wt. $\%$ of $2.58 \% \mathrm{Cu}, 1.73 \% \mathrm{Li}, 0.6 \% \mathrm{Zn}, 0.25 \% \mathrm{Mn}, 0.25 \% \mathrm{Mg}, 0.01 \% \mathrm{Ti}, 0.09 \% \mathrm{Zr}$, $0.03 \% \mathrm{Si}, 0.03 \% \mathrm{Fe}$, and $\mathrm{Al}$ Balance. The alloy was machined into cylindrical fatigue specimens according to ASTM E466 specifications [9]. In order to study the age hardening effect on cyclic stress strain response, three sets of specimens were oil quenched, air cooled, and furnace cooled. Fatigue tests were run with symmetrical uniaxial tension-compression loading at constant test conditions. The specimens were then sectioned along and orthogonal to the specimen's gauge length and polished and etched in sodium hydroxide $(\mathrm{NaOH})$ solution for microstructural characterization.

\section{RESULTS AND DISCUSSION}

\subsection{Cyclic Stress Strain Hysteresis Loop}

The hysteresis loops resulting from the cyclical stress-strain loading (CSS) of three different levels of age hardening were examined. CSS testing mainly focussed on the first few cycles, thus tests were stopped at 200 cycles. Figure 1 shows the CSS hysteresis loop for the oil quenched alloy. This specimen has a smaller hysteresis loop and plastic strain amplitude zone but a higher saturation stress amplitude increases as compared to air and furnace cooled specimens (Figures 2 and 3, respectively). However, as the number of cycles increases from 25 to 50 and to 75 , a slight reduction was observed in the saturation stress amplitude $\left(\Delta \sigma_{s} / 2\right)$ approximately from 770 to 720 and in plastic strain amplitude $\left(\Delta \varepsilon_{\mathrm{pl}} / 2\right)$ as shown in Figure 1 (a), Figure 1 (b), and Figure 1 (c). Oil quenched specimens began to show cyclic softening after approximately 150 cycles as indicated by the width of the hysteresis loop beginning to reduce as shown in Figure 1 (d). 

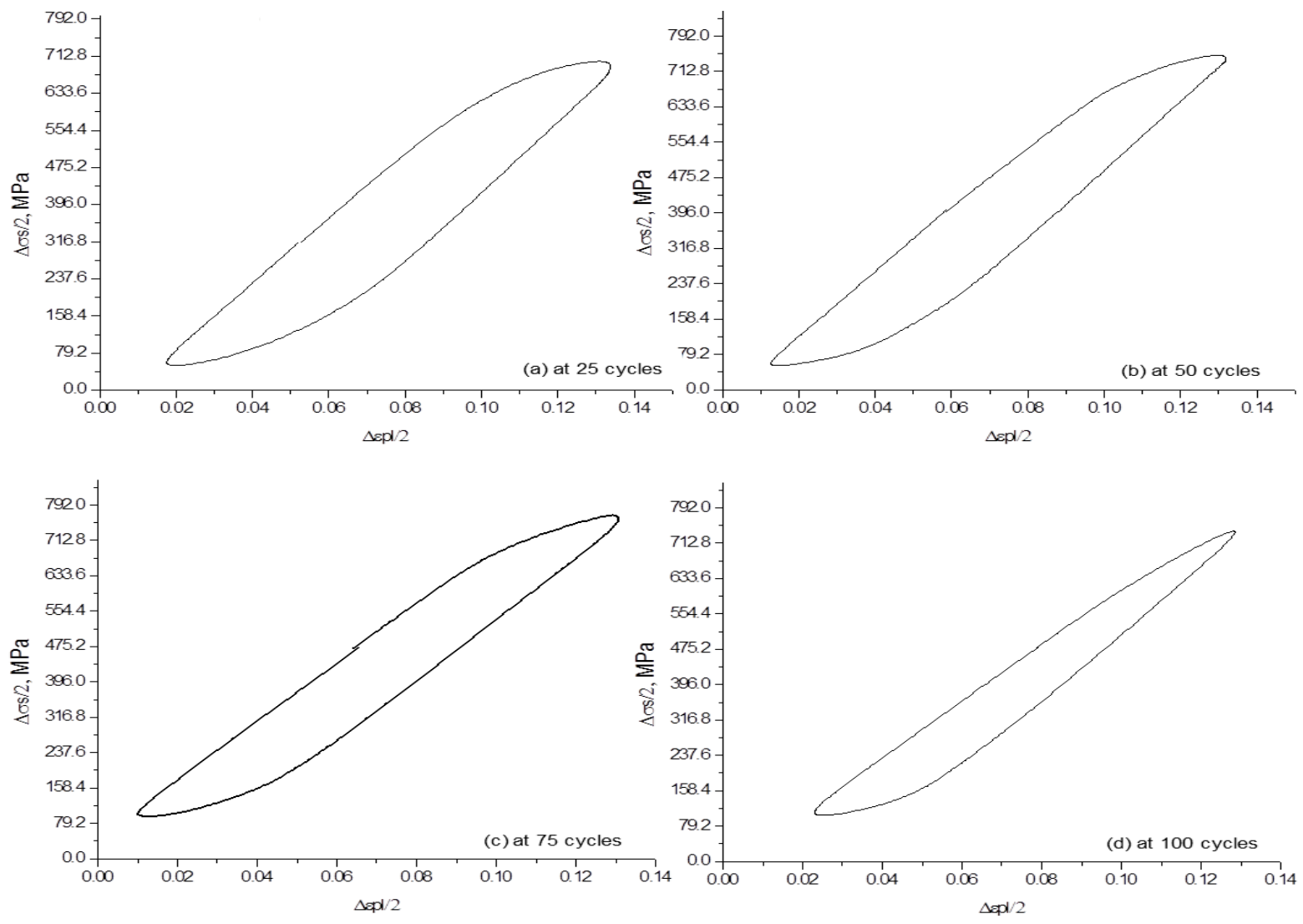

Figure 1 CSS curves of oil quenched alloy C460.

The CSS hysteresis loops (Fig 2) for the air cooled alloy specimens exhibit large plastic strain amplitudes $\left(\Delta \varepsilon_{\mathrm{pl}} . / 2\right)$ zone but lower saturation stress amplitudes as compared to those of the oil quenched alloy specimens (Figure 1). However, as the number of cycles increases from 25 to 50 and to 75 the saturation stress amplitude $\left(\Delta \sigma_{\mathrm{s}} / 2\right)$ increases from 420 to 450 to 500 , respectively, and to 550 over 100 cycles (Figures 2 (a), Figures 2 (b), Figures 2 (c), and Figures 2 (d)).
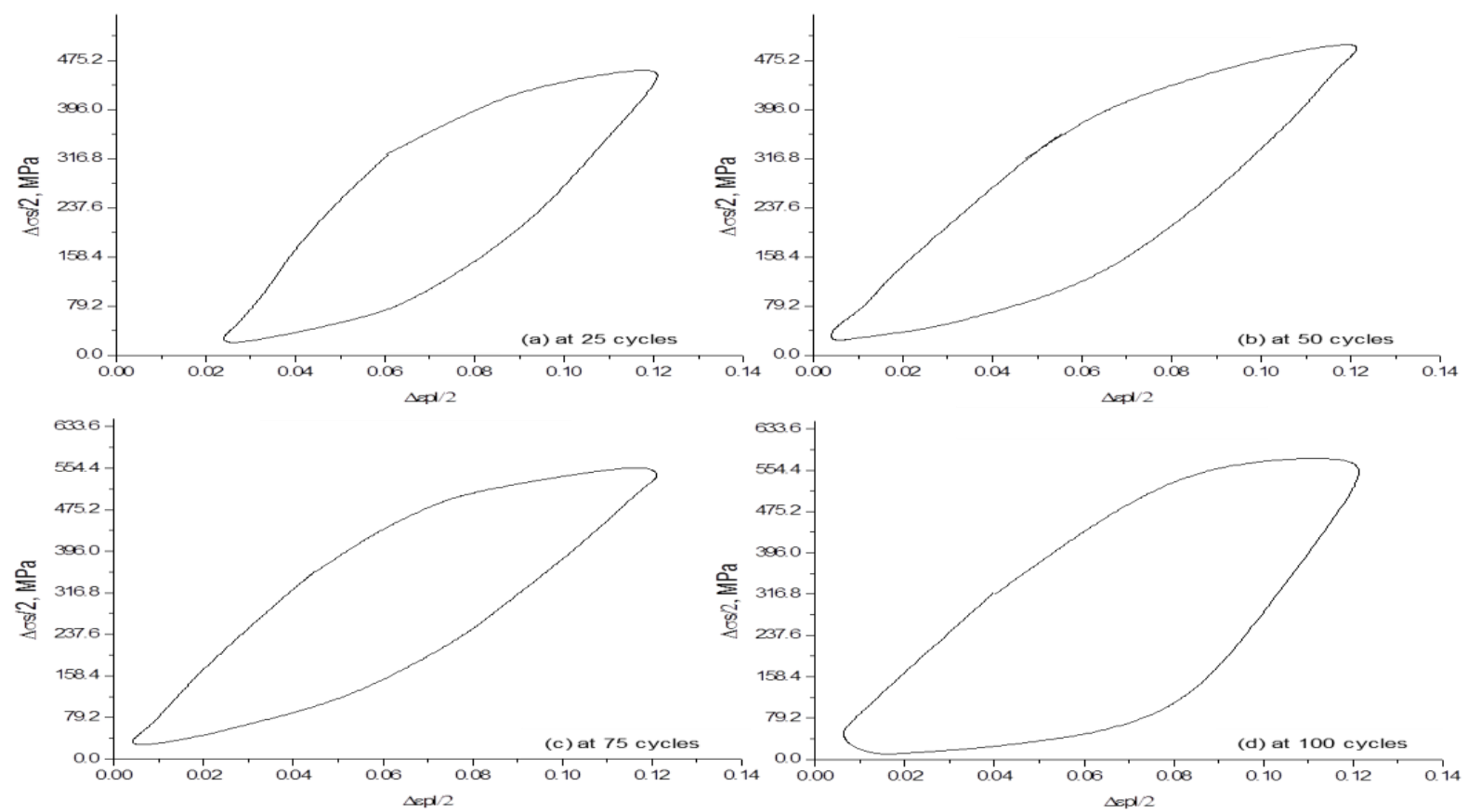

Figure 2 CSS curves of air cooled alloy C460. 
Figure 3 show the CSS hysteresis loops for the furnace cooled alloy specimens. They exhibit larger plastic strain amplitudes $\left(\Delta \varepsilon_{\mathrm{pl}} . / 2\right)$ zone but lower saturation stress amplitudes than air cooled alloy specimens (Figure 2). From this Figure we can observe that the saturation stress amplitude $\left(\Delta \sigma_{s} / 2\right)$ is approximately 250 at 25 cycles, 350 at 50 cycles and increases to 390 at 75 cycles, However, at about 150 cycles the saturation stress amplitude $\left(\Delta \sigma_{s} / 2\right)$ declines to 350 and indicates the specimen experienced softening after being cycle hardened. It may also indicate the specimen has reached failure or is approaching failure.
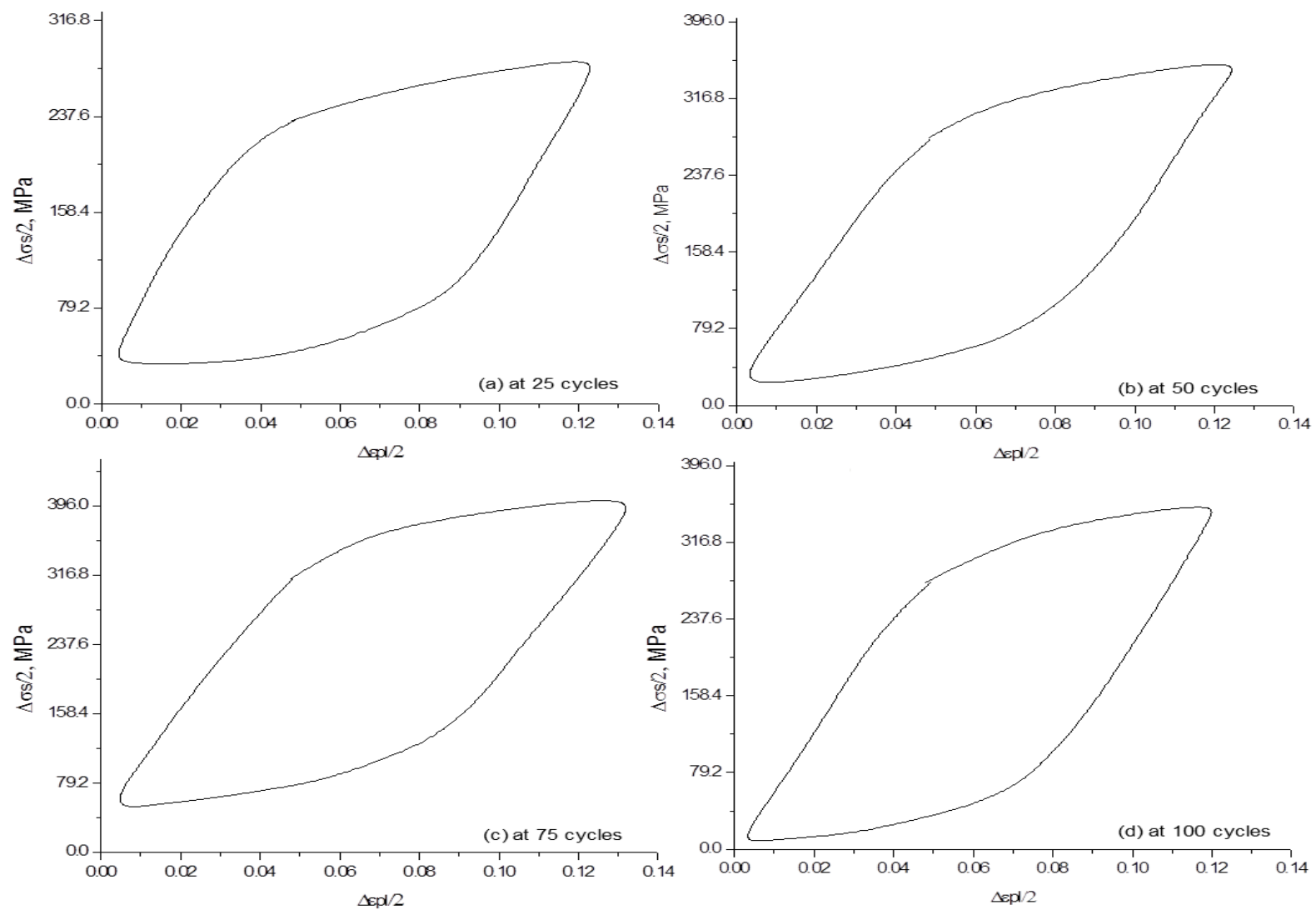

Figure 3 CSS curves of furnace cooled alloy C460.

\subsection{Cyclic Hardening}

The alloy response to cyclic deformation as illustrated by the cyclic hardening curve is shown in Figure 4 for specimens subjected to three different cooling rates and cycled at constant plastic strain amplitude. It was observed that strain hardening was most pronounced in the early stage of cycling. After 50 cycles for all three cooling rates of alloy specimens, the strain hardening becomes saturated and finally the alloy softens. Air cooled and furnace cooled specimens begin to experience softening behavior at approximately 130 cycles, whereas oil quenched specimen maintain a saturation stage until approximately 170 cycles.

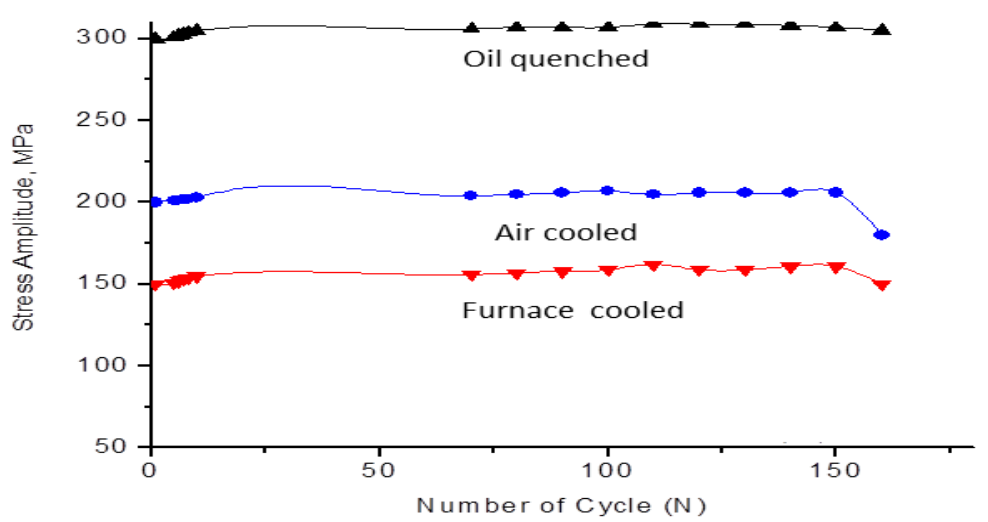

Figure 4 Showing cyclic hardening for three cooling rates of alloy C460. 
The results demonstrate that the initial cyclic hardening rate was strongly influenced by the cooling rate or age hardening applied. In addition, it is also observed that the larger the plastic strain amplitude, the more pronounced the cyclic strain hardening, i.e. stress saturation is reached earlier in the fatigue cycle. Thus, an initial rapid hardening stage followed by cyclic saturation characterizes the cyclic hardening curve of this alloy. It was observed that the shape of a hysteresis loop at saturation depends on the degree of aging.

For faster cooling rates, as in the case of oil quenching, the plastic portion of the loop becomes smaller as shown in Figure 1. For very slow cooling rate the plastic portion becomes much wider (Figure 3). This result is inconsistent with the study performed by Gregson [10].

\subsection{Microstructural Characterization}

All three sets of specimens after cyclical saturation were sectioned longitudinally as well as cross sectioned at the center of the specimen's gauge length, and underwent a delicate process of polishing and etching with sodium hydroxide $(\mathrm{NaOH})$ solution in order to reveal and to correlate the results of the macro-scale (cyclic stress strain response) to the micro-scale (microstructural characterization with SEM).

Figure 5 shows the microstructure of oil quenched specimens at low (Fig 5(a)) and high (Fig 5(b)) magnifications, respectively. These images show no distinctive features of grains or grain boundaries that indicate a PFZ.

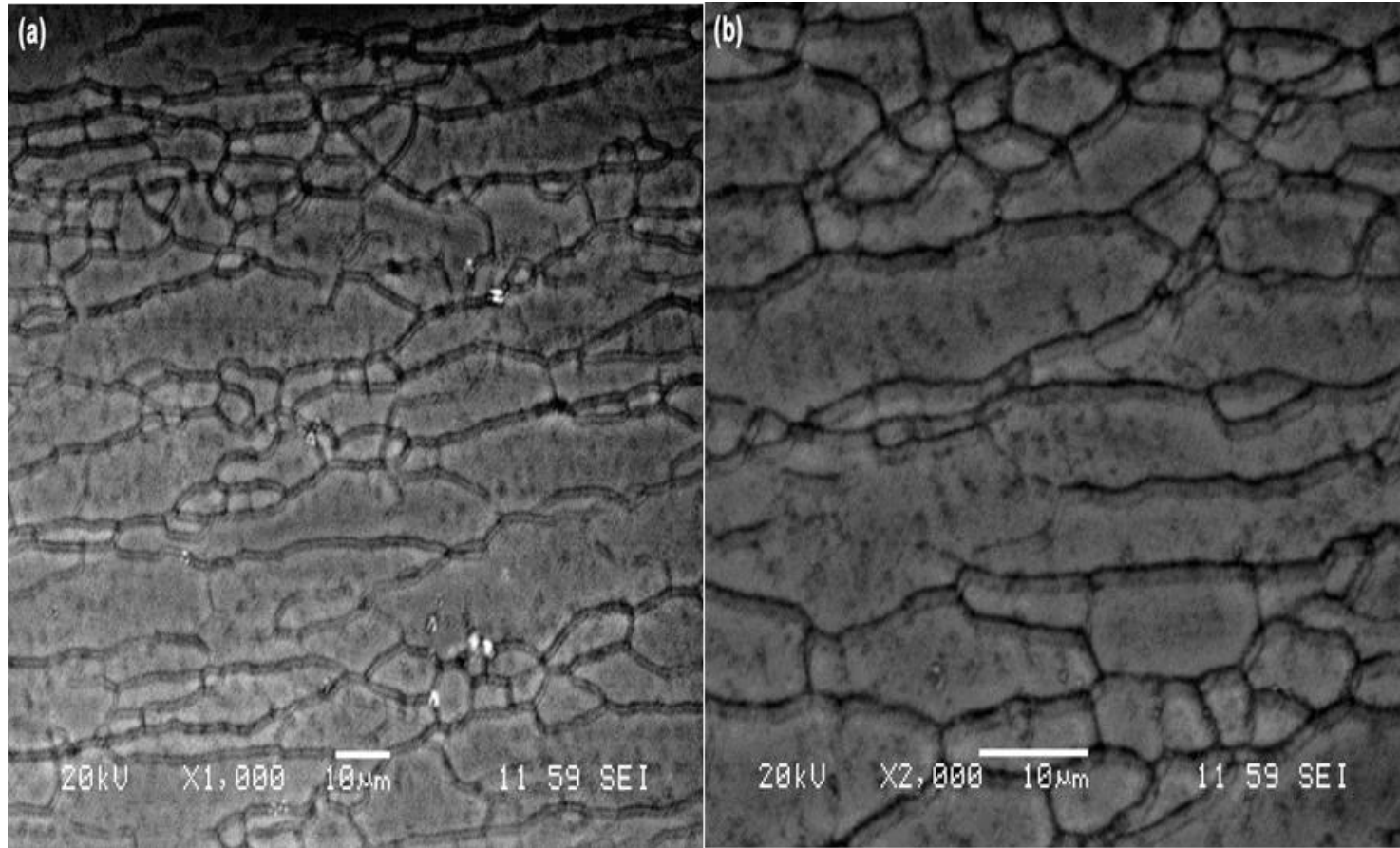

Figure 5 SEM images of oil quenched for alloy C460 no evidence of precipitates free zones PFZ.

The image shows solid grain boundaries which is interpreted as meaning the precipitates within grain boundaries are small and continuous and there was insufficient time to allow precipitates within grain boundaries to grow at the expense of adjacent precipitates and thus form what the author calls "precipitates free zones." The absence of PFZ's is the result of a fast cooling rate.

Figure 6 and Figure 7 show the microstructure for air and furnace cooled specimens, respectively. From these images one can detect an intermediate region between grains and grain boundaries called the precipitates free zone (PFZ) which contain no precipitates. Owing to the slow cooling rate the precipitates that can be found within grain boundaries have sufficient time to grow. Precipitates that were initially in the PFZ have moved towards grain boundaries and precipitates within grain boundaries grow at the expense of the precipitates adjacent to grain boundaries. Further, precipitates can be clearly observed within the grains and within the grain boundaries as distinct regions (Figure 7 (a) and Figure 7 (b) at low and high magnification, respectively). 

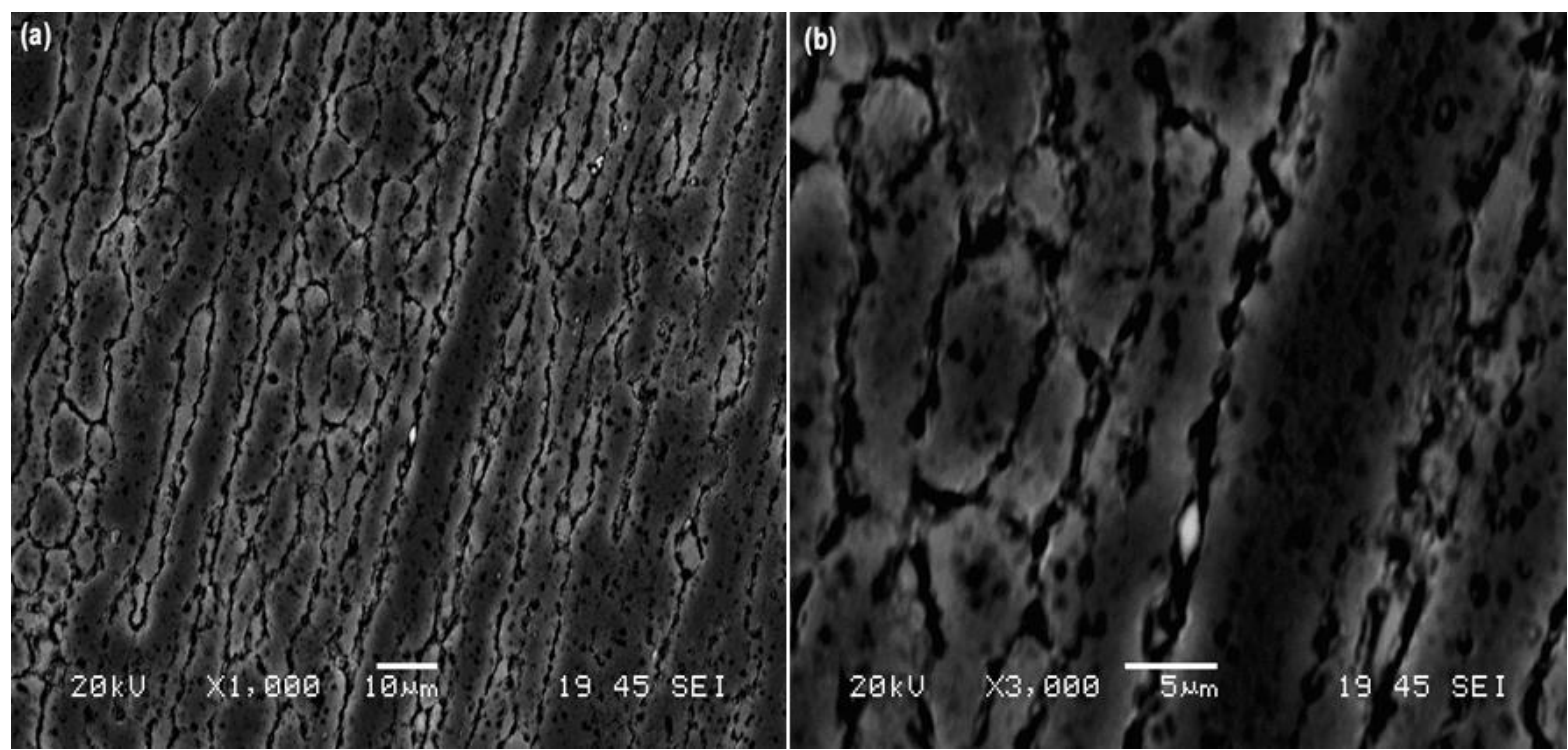

Figure 6 SEM image of air cooled alloy C460 showing precipitates free zones (PFZ) along grain boundaries.
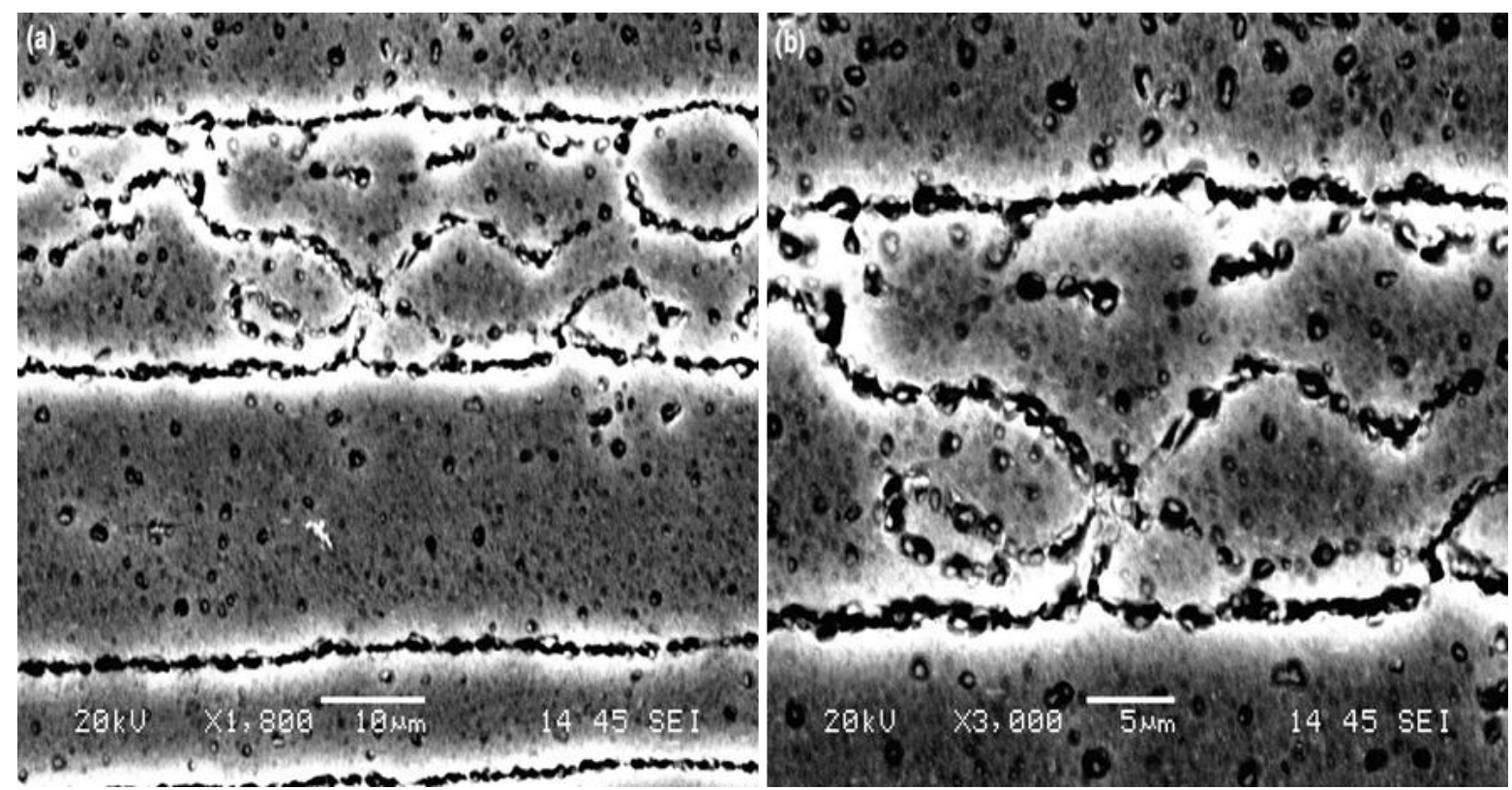

Figure 7 SEM image of furnace cooled for alloy C460 showing a distinct precipitates free zone (PFZ) along grain boundaries.

In most cases, precipitate free zones are not considered as strengthening zones but rather could lead to stress concentrations and sites for crack initiation. This may account in particular for the specimens of air and furnace cooled exhibiting lower saturation stresses as shown in Figure 2 and Figure 3, respectively. Further, earlier cyclic softening is observed than for oil quenched specimens as shown in Figure 4. There was no evidence of slip deformation bands in specimens from any of the three methods of age hardening and at any plastic strain amplitude, although all these specimens were cyclically deformed. A similar study done by the author [11] on aluminum copper alloys Al-2024 also found no slip bands after fatigue testing, thus agreeing with the current study. The mechanism behind the phenomena is, however, unclear.

\section{CONCLUSION}

Cyclic stress-strain responses and saturation stress amplitudes from stress-strain cycling of alloy C460 indicated oil quenched specimens have a higher saturation stress than air and furnace cooled specimens. The author believes this is due to the absence of precipitate free zones (PFZ) in oil quenched as compared to air and furnace cooled specimens that have PFZ's It was observed that PFZ's occur adjacent to grain boundaries owing to the slow cooling rate which allows precipitates at grain boundaries to grow at the expense of the precipitates adjacent to the grain boundaries. 


\section{ACKNOWLEDGEMENTS}

The author acknowledges and thanks Mr. Todd K. Cogswell from Alcoa Aerospace Engineered Products for his advice and for providing the material.

\section{REFERENCES}

[1] K. Welpmann, M. Peters, and T.H. Sanders, Aluminum-lithium alloys, Aluminum, 60(10), 1984, 641646.

[2] J.B. Wert, and J.B. Lumsden, Intergranular fracture in an Al- $\mathrm{Li}-\mathrm{Cu}-\mathrm{Mg}-\mathrm{Zr}$ alloy, Spectra Metallurgical $19,1985,205-209$.

[3] A.R.C., Westwood, New materials for aerospace industry, Material Science and Technology, 6, 1990, 958-961.

[4] T.H. Sanders, and E.A. Starke, The effect of slip distribution on the monotonic and cyclic ductility of AlLi binary alloys, Acta Metallurgical, 30, 1982, 927-939.

[5] D. Webster, The effect of low melting point impurities on the properties of Al-Li alloys. Metallurgical Transaction, A18,1987, 2187-2193.

[6] N. Eswara Prasad, and P. Rama Rao, Low cycle fatigue resistance in Al-Li alloys, Material Science Technology, 16, 2000, 408-426.

[7] C.J. Peel, D. McDarmaid, B. Evans, Considerations of critical factors for the design of aerospace structures using current and future aluminum-lithium alloys, in: R.J. Kar, S.P. Agrawal, W.E. Quist (Eds.), Proceedings of the Conference on Aluminum-Lithium Alloys-Design, Development and Applications Update, ASM International, Metals Park, OH, USA, 1988, 315-337.

[8] E.J. Coyne, T.H. Sanders, and E.A. Starke, The effect of microstructure and moisture on the low cycle fatigue and fatigue crack propagation of two $\mathrm{Al}-\mathrm{Li}-\mathrm{X}$ alloys. In Al-Li Alloys (eds), Warrendale, PA: Metallurgical Society AIME, 1981, 293-305.

[9] American Society for Metals (ASM), Metals Handbook Desk Edition, 1985, p.7.

[10] P.J. Gregson, and H.M. Flower microstructural control of toughness in Al-Li alloys, Acta Metallurgical, 33, 1985, 527-537.

[11] A. Mohamed, Y. El-Madhoun and M.N. Bassim, The effect of tempering on low cycle fatigue behavior of 2024 polycrystalline aluminum alloy, Journal of Material Processing Technology, 162, 2005, 362-365. 